\title{
RENDA DA TERRA AGRÍCOLA EM NEPOMUCENO - MG ${ }^{1}$
}

\author{
Lucas Guedes Vilas Boas ${ }^{2}$
}

\begin{abstract}
Resumo
O intuito deste artigo é discutir as formas de renda da terra agrícola existentes no município de Nepomuceno. As categorias de renda fundiária formuladas por Karl Marx forneceram o aporte teórico-metodológico para a construção da análise realizada. Ademais, objetivou-se explicar o processo de especulação imobiliária e fundiária vigente em Nepomuceno, o qual favorece os arrendamentos, muito presentes na realidade municipal. Ênfase foi conferida à renda da terra diferencial, a qual atua intensamente em terras nepomucenenses. Tanto a renda diferencial I, vinculada à localização e à fertilidade natural dos solos, quanto a renda diferencial II, atrelada à aplicação de capitais e técnicas nos solos, foram analisadas neste texto.
\end{abstract}

Palavras-chaves: Renda da Terra; Nepomuceno; Arrendamentos.

\section{AGRICULTURAL LAND RENT IN NEPOMUCENO - MG}

\begin{abstract}
The purpose of this article is to discuss the agricultural land rent forms in Nepomuceno. The categories of land rent formulated by Karl Marx provided the theoretical and methodological support for the construction of the analysis. Furthermore, the intention was to explain the process of land and property speculation current in Nepomuceno, which favors the leases, very present in the municipal reality. Emphasis was given to the differential land rent, which is sorely active in nepomucenenses lands. Both the differential rent I, linked to the localization and the natural fertility of the soil, and the differential rent II, linked to the application of capital and techniques in soils, were analyzed in this paper.
\end{abstract}

Keywords: Land Rent; Nepomuceno; Leases.

\section{RENTA DE LA TIERRA AGRÍCOLA EN NEPOMUCENO - MG}

\section{Resumen}

El propósito de este artículo es discutir las formas de renta de la tierra agrícola existentes en el municipio de Nepomuceno. Las categorías de renta de la tierra formuladas por Karl Marx proporcionaron el aporte teórico y metodológico para la construcción del análisis realizado.

\footnotetext{
${ }^{1}$ Este artigo é parte da dissertação de Mestrado apresentada ao Programa de Pós-Graduação em Geografia da Universidade Federal de Juiz de Fora, com financiamento da Coordenação de Aperfeiçoamento de Pessoal de Nível Superior (CAPES).

${ }^{2}$ Licenciado, Bacharel e Mestre em Geografia pela Universidade Federal de Juiz de Fora (UFJF) e Doutorando em Geografia pela Universidade Federal de Minas Gerais (UFMG). Professor do Centro Federal de Educação Tecnológica de Minas Gerais (CEFET/MG).
} 
Además, un objetivo es explicar el proceso de especulación inmobiliaria y del suelo presente en Nepomuceno, que favorece los arrendamientos, muy presentes en la realidad municipal. Énfasis fue dada a la renta de la tierra diferencial, la cual actúa intensamente en tierras nepomucenenses. Tanto la renta diferencial I, vinculada con la ubicación y la fertilidad natural del suelo, como la renta diferencial II, relacionada a la aplicación de capital y técnicas en los suelos, fueron analizadas en este trabajo.

Palabras clave: Renta de la tierra; Nepomuceno; Arrendamientos.

\section{INTRODUÇÃO}

A renda da terra é uma categoria de análise que possibilita a identificação de vários processos concernentes à questão agrária, principalmente aqueles nitidamente capitalistas. Além disto, permite também a compreensão de diversos fatos ocorridos no campo, como o processo de especulação fundiária, a aplicação de capitais na atividade agrícola, entre outros.

Neste contexto, as informações referentes à renda da terra no município de Nepomuceno foram obtidas por intermédio de observação em campo, entrevistas e diálogos com os proprietários agrícolas municipais, além de informações sobre o preço da terra, a mecanização e a produção agrícolas, entre outros assuntos pertinentes ao estudo realizado. Para tal intento, as bibliografias referentes às temáticas retrocitadas foram de grande valia quando conjugadas aos dados analisados.

A exiguidade de dados e informações alusivos à quantidade total de arrendamentos em Nepomuceno, bem como aos valores destes, compôs um empecilho à análise da renda fundiária municipal, sobretudo quanto aos elementos quantitativos. Assim sendo, estes escritos enfatizaram as formas como a renda da terra agrícola ocorre no contexto municipal. A não utilização de dados e/ou valores quantitativos acerca da renda fundiária é justificada pela inacessibilidade a tais informações.

Para a compreensão da renda fundiária em Nepomuceno, é importante o conhecimento da estrutura fundiária municipal. Com base nas informações fornecidas pela Prefeitura Municipal de Nepomuceno no ano de 2015, concernentes aos imóveis rurais cadastrados no Instituto Nacional de Colonização e Reforma Agrária (INCRA), o município possuía 2272 minifúndios, 494 pequenas propriedades rurais, 94 médias propriedades rurais e apenas 5 grandes propriedades rurais.

Esta classificação dos imóveis rurais de Nepomuceno foi realizada com base na Lei $\mathrm{n}^{\circ}$ 8.629, de 25 de fevereiro de 1993 (BRASIL, 1993). De acordo com a referida legislação, os 
minifúndios têm até um módulo fiscal ${ }^{3}$, as pequenas propriedades rurais variam de um a quatro módulos fiscais, as médias propriedades têm entre quatro e quinze módulos fiscais e as grandes propriedades rurais possuem mais de quinze módulos fiscais.

Hodiernamente, a economia do município de Nepomuceno está assentada sobre a agricultura, principalmente a produção cafeeira, a qual é responsável por aproximadamente $70 \%$ do PIB (Produto Interno Bruto) municipal. Segundo informações divulgadas pelo IBGE (2013), no ano de 2013, Nepomuceno era o sétimo maior produtor de café do país, com um total de 26838 toneladas colhidas. Todavia, a produção municipal pode ter sido superior aos dados fornecidos pelo IBGE, visto que muitos produtores revelaram a omissão de parte da produção aos órgãos oficiais, visando a redução dos impostos pagos.

Também têm algum destaque no município a avicultura, com a presença do Aviário Santo Antônio, e a produção de milho, arroz e feijão, cuja maioria dos grãos colhidos é destinada ao consumo próprio, enquanto um pequeno percentual é direcionado à venda para estabelecimentos comerciais de Nepomuceno e dos municípios adjacentes.

Quanto à pedologia, encontram-se no município latossolos vermelho-amarelo álico, latossolos vermelho escuro distrófico, cambissolos álico e podzólico vermelho-amarelo álico ou distrófico, respectivamente nesta ordem em termos de área ocupada (BRASIL, 1983).

Deste modo, o objetivo do artigo é discutir as formas de renda da terra agrícola atuantes no município de Nepomuceno, sobretudo a renda diferencial, associando-as às relações de trabalho e de produção vigentes na realidade municipal, aos arrendamentos, às estratégias para aumento da produtividade, entre outros motes atinentes ao assunto em questão.

\section{METODOLOGIA}

A leitura e a análise de referências bibliográficas concernentes à temática discutida forneceram o aporte teórico-metodológico para a pesquisa. Conforme narra Oliveira (2012), a pesquisa bibliográfica utilizada se baseia no uso, na leitura e na análise de fontes científicas relativas ao tema pesquisado. Para a autora, a pesquisa bibliográfica dialoga com outros

\footnotetext{
${ }^{3}$ Neste quesito, salienta-se que o valor do módulo fiscal é medido em hectares e varia conforme o município analisado. Em Nepomuceno, o valor do módulo fiscal é de vinte e seis hectares. Alguns aspectos são considerados para a determinação do valor de módulo fiscal de cada município, como o tipo de exploração da terra predominante (hortifrutigranjeira, cultura permanente, temporária, pecuária ou florestal) e a renda extraída com esta atividade no município, assim como ações exploratórias secundárias que sejam relevantes devido à área ocupada e/ou à renda gerada.
} 
conhecimentos e fornece o subsídio teórico necessário ao trabalho de campo. No intuito de conjugar teoria e prática, as obras analisadas subsidiaram as idas a campo, as quais ocorreram entre os dias de 19 de novembro de 2014 e 19 de julho de 2015.

Nos dizeres de Lacoste (2006), o trabalho de campo necessita de um período mínimo de convivência na área de estudo. Para além, o geógrafo francês afirma que a teoria deve respaldar as pesquisas de campo, para que estas não se tornem mero empirismo. Destarte, o tempo de duração do trabalho de campo foi de suma importância ao estudo realizado, pois favoreceu a compreensão de fenômenos atrelados à renda da terra em Nepomuceno.

Neste âmbito, o diálogo com os proprietários fundiários em Nepomuceno, assim como a observação das formas de trabalho e produção vigentes no panorama agrário local, foram valorosos ao trabalho realizado, pois propiciaram maior conhecimento acerca da dinâmica da renda fundiária municipal e dos arrendamentos realizados nas propriedades agrícolas nepomucenenses.

Ademais, as informações relativas às variações dos preços venais de imóveis e terrenos, tanto urbanos, quanto rurais, foram fornecidas pela Prefeitura Municipal de Nepomuceno e por algumas imobiliárias atuantes no município. Os dados obtidos através da Prefeitura referem-se a uma pesquisa amostral realizada anualmente pelo órgão com a finalidade de recadastramento imobiliário para a cobrança do Imposto Predial Territorial Urbano (IPTU). Os terrenos e imóveis foram escolhidos aleatoriamente e se situam em diversos pontos do município, tanto na cidade, quanto no campo.

As imobiliárias municipais também cederam informações alusivas aos preços estimados de venda de imóveis e terras em diversas áreas do município. Os dados concedidos por ambas as entidades se referem aos preços venais das propriedades fundiárias e imobiliárias entre os meses de janeiro de 2005 e dezembro de 2014, com informações relativas a todos os anos deste intervalo temporal.

As entrevistas semiestruturadas também foram utilizadas como meio de avaliação das formas de renda fundiária presentes em Nepomuceno. De acordo com Triviños (1995), este tipo de entrevista possui um eixo norteador através do qual algumas perguntas são formuladas com fundamentação em conhecimentos teóricos e hipóteses acerca do tema pesquisado. Gil (2002) denomina este tipo de entrevista como parcialmente estruturada. Em seus dizeres, a entrevista "pode ser parcialmente estruturada, quando é guiada por relação de pontos de interesse que o entrevistador vai explorando ao longo de seu curso" (GIL, 2002, p. 117). 
Destarte, nas entrevistas realizadas, os questionamentos realizados sempre intentavam a obtenção de informações acerca da questão agrária municipal e, sobretudo, da renda da terra.

\section{DESENVOLVIMENTO}

Após a chegada da Unidade IX do Centro Federal de Educação Tecnológica (CEFET/MG) na cidade, no ano de 2007, observou-se um elevado acréscimo nos preços imobiliários e fundiários, seja para aluguel ou compra, sobretudo nas áreas mais próximas ao edifício da referida instituição de ensino. Esta oscilação nos preços possui liames estreitos com a problemática da renda fundiária, visto que a construção do prédio do CEFET/MG melhorou significativamente o atributo localização do município, principalmente de sua rede urbana.

Com isso, houve a valorização de seus imóveis e suas porções de solo, além do impulso à migração para o município. Dados recentes fornecidos pelo IBGE (1991, 2000, 2010) ilustram que entre os anos de 2000 e 2007 houve um descenso demográfico na área estudada (fato comum nas pequenas cidades do país no último decênio), enquanto nos anos seguintes, o quantitativo populacional apresentou expressivo crescimento. A tabela 01 corrobora esta variação populacional ocorrida em Nepomuceno:

Tabela 01: População Total Residente em Nepomuceno-MG.

\begin{tabular}{c|c}
\hline 1991 & 24.069 \\
2000 & 24.822 \\
2007 & 24.430 \\
2010 & 25.733 \\
$2015^{4}$ & 26.897 \\
\hline
\end{tabular}

Anualmente, a Prefeitura Municipal de Nepomuceno efetua uma pesquisa para o recadastramento de imóveis, com a finalidade de atualizar as informações para a cobrança de impostos, como o IPTU (Imposto Predial Territorial Urbano). Neste estudo, o órgão efetua uma amostragem, na qual seleciona aleatoriamente alguns imóveis e terrenos, de diferentes locais na área urbana e na rural, para calcular o seu valor venal.

Assim sendo, foram cedidos pela Prefeitura ${ }^{5}$ os dados referentes ao preço estimado

\footnotetext{
${ }^{4} \mathrm{O}$ valor apresentado para a população de Nepomuceno no ano de 2015 é uma estimativa gerada pelo Instituto Brasileiro de Geografia e Estatística (IBGE), com base em diversos cálculos e métodos estatísticos realizados.
} 
dos imóveis e terrenos no município no período compreendido entre janeiro de 2005 e dezembro de 2014. Posteriormente, já com a posse destes números, eles foram tabulados, de modo a possibilitar o cálculo da variação dos preços fundiários e imobiliários do município nos últimos anos. Mesmo sem abranger a totalidade dos imóveis e terrenos de Nepomuceno, tais informações possuem enorme relevância, visto que as amostragens são um tipo de pesquisa utilizado para amplas áreas, por renomadas entidades como o IBGE, entre outras.

Esmiuçando os dados fornecidos pela Prefeitura Municipal de Nepomuceno, evidencia-se que a especulação imobiliária e fundiária no município tornou-se mais intensa a partir do ano de 2007, data da implantação do Campus IX do Centro Federal de Educação Tecnológica de Minas Gerais (CEFET-MG) no município. Isto demonstra como a chegada de uma entidade prestadora de serviços numa cidade pode acarretar em significativas mudanças em seu cotidiano e em sua economia, ratificando o ganho de importância do setor terciário na economia contemporânea, conforme apontam autores como Santos (2008), ao discutir os circuitos superior e inferior da economia urbana.

De acordo com os dados do IPCA (Índice de Preços ao Consumidor Ampliado), indicador mais utilizado para este tipo de cálculo no Brasil, medido pelo IBGE, a inflação acumulada no país de janeiro de 2005 a dezembro de 2014 foi de 69,24\%. No mesmo intervalo de tempo, segundo as informações concedidas pela Prefeitura Municipal e por algumas imobiliárias ${ }^{6}$ da cidade, a variação de preços dos imóveis urbanos no município fícou entre $350 \%$ e $450 \%$, enquanto os preços dos terrenos urbanos apresentaram um aumento entre $600 \%$ e $700 \%$ no mesmo período.

No tocante aos imóveis e às terras rurais, estes apresentaram um aumento de preço

\footnotetext{
${ }^{5}$ A Prefeitura Municipal de Nepomuceno gentilmente forneceu as informações referentes à pesquisa por amostragem realizada com o intuito de recadastrar alguns imóveis para adaptação dos impostos cobrados, como o IPTU (Imposto Predial Territorial Urbano). Neste estudo da Prefeitura, foram selecionados aleatoriamente imóveis e terras em diferentes bairros da cidade e também na zona rural, ambicionando calcular o preço corrente de venda dos mesmos. Esclarece-se aqui, que os mesmos imóveis e terrenos foram analisados ano após ano, elevando a confiabilidade dos dados obtidos. Destarte, com a posse das informações referentes ao preço venal dos terrenos e imóveis durante o período de dez anos, foi possível calcular a variação percentual do preço de cada um deles anualmente e durante o decênio em questão. Neste sentido, salienta-se que a Prefeitura Municipal levantou os preços ano a ano por um período de dez anos.

${ }^{6}$ Seguindo o mesmo procedimento executado com as informações cedidas pela Prefeitura Municipal de Nepomuceno, os dados disponibilizados pelas imobiliárias também foram sistematizados, de modo a possibilitar o cálculo da variação de preços imobiliários e fundiários no intervalo analisado. Tanto as imobiliárias, quanto a Prefeitura Municipal de Nepomuceno, forneceram dados referentes aos preços estipulados de venda de terrenos e imóveis urbanos e rurais no intervalo temporal compreendido entre janeiro de 2005 e dezembro de 2014. Estas informações concernem a todos os bairros do município e os imóveis pesquisados foram escolhidos aleatoriamente.
} 
entre 150 e $250 \%$ nos dez anos analisados. Embora a valorização das propriedades rurais em Nepomuceno tenha sido menor em comparação às terras e imóveis urbanos, não pode ser menosprezada, pois representou uma elevação significativa nos preços rurais do município, fomentando diversos processos na realidade agrícola local. Para além, cabe salientar que a terra, dependendo do momento histórico, se encarece mais rapidamente que outras mercadorias, devido à sua não reprodutibilidade.

Comparando a variação dos preços imobiliários e fundiários no município com a inflação somada nestes dez anos no país, constata-se que o aumento do preço de venda dos imóveis e terras nepomucenenses foi amplamente superior à inflação no mesmo período. É importante ressaltar a correlação existente entre a valorização fundiária e imobiliária e os arrendamentos, em âmbito geral. No panorama municipal, a valorização de imóveis e terras influenciou no encarecimento dos arrendamentos.

Nesta celeuma, pode-se dizer que, em síntese: “A renda fundiária se configura em determinada quantia que o proprietário do solo recebe anualmente pelo arrendamento de um pedaço do globo terrestre" (MARX, 1983, p. 714). Neste encadeamento, deve-se sublinhar que os proprietários fundiários, por intermédio das relações contratuais, podem escolher a maneira como desejam receber a renda fundiária, cuja obtenção pode ocorrer de modo gradativo, através dos arrendamentos, ou em uma única parcela, por meio da venda da terra.

Em diálogos com proprietários fundiários do município, estes noticiaram um expressivo acréscimo nos preços dos arrendamentos, fator que tornou mais atrativa a ação de arrendar suas terras. Neste mote, de acordo com a assinatura do contrato, a duração do arrendamento pode variar, assim como o percentual dos lucros ou da produção direcionados ao pagamento do proprietário do solo (MARX, 1983; OLIVEIRA, 2007).

Vários dos agricultores familiares investigados enumeraram expressivos acréscimos nos impostos rurais, como o ITR (Imposto Sobre a Propriedade Territorial Rural), além da instituição do CAR (Cadastro Ambiental Rural), indispensável a todas as propriedades rurais, segundo a legislação nacional. O Cadastro Ambiental Rural é uma obrigação decorrente do Novo Código Florestal. Segundo as informações cedidas pela Prefeitura Municipal de Nepomuceno, o cadastro já abrange 46252,13 hectares do total de 60934,13 hectares de imóveis rurais do município. Para além, os indivíduos pesquisados na urbe nepomucenense destacaram o relevante aumento no IPTU (Imposto Predial Territorial Urbano) nos últimos anos. 
Tais fatos elevam as despesas com o pagamento de tributos, comprometendo um percentual significativo dos orçamentos familiares. Em consonância com os dizeres de Lefebvre (1999), pode-se afirmar que com o crescimento dos valores dos impostos, uma parcela maior da mais-valia global é captada e retida pelos Estados por intermédio do sistema fiscal. Em seus dizeres:

\begin{abstract}
A massa da mais-valia se distribui entre suas diversas frações, inclusive, os proprietários da terra, os comerciantes, as profissões ditas liberais etc. Essa distribuição se efetua no nível global. O Estado a supervisiona, impedindo os excessos demasiadamente brutais. Por outro lado, ele retém uma parte considerável da mais-valia, por meio do sistema fiscal em particular, para manter a vida na sociedade, o saber e o ensino, o exército e a polícia, a burocracia e a cultura etc. (LEFEBVRE, 1999, p. 138)
\end{abstract}

De maneira geral, as classes detentoras das terras, exercendo o monopólio sobre elas, arrendam-nas, cobrando taxas pelo seu uso e pelo direito dos arrendatários nela produzirem. Nos dizeres de Marx (1983), esta situação configura a formação da renda absoluta, a qual decorre da propriedade privada do solo, resultando de sua limitada quantidade e de seu monopólio por alguns grupos.

Nela, a renda fundiária é fração da mais-valia global, paga por toda sociedade ao proprietário fundiário. Neste sentido, Milton Santos (2006) compreende a mais-valia global como a mola propulsora das ações nas economias capitalistas, com os monopólios conformando-se como uma das artimanhas arquitetadas para extração de parcelas desta maisvalia mundial. Assim como advoga Oliveira (1981), no momento da aquisição da terra, o capitalista compra também a renda da terra, a garantia de apropriação de uma parcela da maisvalia global, retirada da totalidade da sociedade.

Conforme enunciam os dizeres de Marx (1983), a renda absoluta também deriva da diferença entre preço do produto e preço de mercado, sendo esta a segunda possibilidade para sua origem. Portanto, até o "pior solo" consegue auferi-la. Todavia, solos de maior fertilidade extraem maior quantidade de renda absoluta. Então, esta forma de renda é obtida de duas maneiras distintas, cujos mecanismos foram acima aventados. Uma delas é por intermédio dos arrendamentos, enquanto a outra advém da venda das mercadorias a um preço superior ao de produção (MARX, 1983).

Portanto, a extração de renda absoluta é intensa na conjuntura nepomucenense, visto que os arrendamentos são frequentes na realidade local. Ademais, assim como esclareceram em seus próprios relatos, os agricultores municipais comercializam seus produtos acima do 
preço de produção, obtendo destarte, a renda absoluta. Aliás, no modo de produção capitalista, não é surpresa tal conduta, visto que um de seus objetivos primordiais é o lucro.

Em Nepomuceno, a maioria dos arrendamentos acontece entre os pequenos proprietários agrícolas, os quais arrendam suas terras principalmente para o cultivo da monocultura cafeeira, base da agricultura municipal. Os arrendatários, em geral, são moradores do município, que possuem diminutas extensões de terra ou nenhuma terra, e enxergam no arrendamento uma possibilidade de aumento de seus orçamentos.

O sistema de parceria, um dos tipos de trabalho vigentes na agricultura municipal, aparece como um modo de renda fundiária existente no campo em Nepomuceno. Nos dizeres de Marx (1983, p. 920), ele:

\footnotetext{
Pode ser considerado forma transitória entre a primitiva forma de renda e a capitalista, o sistema de parceria ou de repartição dos frutos da exploração no qual o agricultor (arrendatário) emprega, além de trabalho próprio ou alheio, parte do capital operante, e o proprietário fornece, além da terra, a outra parte desse capital (gado, por exemplo), sendo o produto dividido entre ambos em determinadas proporções que variam segundo os países.
}

Assim como o autor explicou, na parceria não é obrigatório o pagamento de uma taxa pela utilização da terra. O proprietário fundiário e o arrendatário compartilham os produtos derivados da exploração do solo, sendo que o último deve entregar parte de sua produção ou dos lucros ao dono das terras. Ademais, a aplicação de capital para o trabalho agrícola também é dividida.

Em Nepomuceno, observou-se que a parceria é necessária, em alguns casos, aos arrendatários, pois estes não dispõem de recursos ou capitais para a obtenção de uma produtividade satisfatória. Ambicionando ganhos produtivos, eles se submetem à exploração notadamente capitalista, visando sua subsistência e de seus familiares, bem como o acréscimo da receita mensal e/ou anual. Alguns dos arrendatários investigados afirmaram que a assinatura do contrato de parceria lhes assevera uma maior produção total e o aumento dos orçamentos médios, mesmo com a obrigatoriedade da cessão de um percentual dos lucros.

Aos detentores das terras arrendadas através do sistema de parceria, interessa tal modalidade de contrato agrário, visto que auferem lucros em solos outrora improdutivos. Esta ação geralmente é realizada com o objetivo de ampliar os rendimentos obtidos, sobretudo em momentos de dificuldade financeira (COSTA NETO, 1998). Isto não difere das descrições oferecidas pelos proprietários fundiários nepomucenenses, os quais arrendam porções de solo 
a terceiros por intermédio das parcerias. Eles disseram que tal prática é vantajosa, pois os indivíduos que alugam o solo dependem daquela produção para subsistirem. Neste intuito, empenham-se o máximo para extrair a maior produtividade possível do solo, provocando acréscimos no total de trabalho fornecido e de produtos colhidos.

Ainda se referindo a este modo de arrendamento, uma prática corriqueira no campo nepomucenense é a "meia", denominação atribuída pelos locais ao contrato instituído, no qual, o proprietário fundiário empresta equipamentos e dinheiro aos arrendatários, os quais devem ceder metade do total produzido ao proprietário fundiário, como forma de pagamento pelo uso de suas terras.

As terras situadas no município de Nepomuceno extraem renda da terra diferencial I, em razão de sua privilegiada localização geográfica, fixando-se nas adjacências de trajetos que ligam diversas cidades a importantes capitais nacionais, como São Paulo e Belo Horizonte. Esta circunstância facilita o escoamento da produção, especialmente a cafeeira, para outras localidades, tornando sua localização melhor que a da maioria dos demais lugares.

Assim como argumentam autores como Marx (1983) e Lefebvre (1999), na renda diferencial I, a quantidade de capital e de trabalho aplicada no solo é desconsiderada. Oliveira (2007) mostra que esta renda advém da localização e da fertilidade natural dos solos. Lefebvre (1978) e Marx (1983) afirmam que a renda diferencial I é auferida nas melhores terras, em virtude da diferença de produtividade entre as porções de solo, resultante da maior fertilidade natural de alguns deles e /ou de sua privilegiada localização.

Destarte, ela é obtida em virtude de diferenças naturais existentes entre os terrenos, as quais correspondem a aspectos atrelados à proximidade em relação às vias de comunicação e aos mercados e à fertilidade natural (LEFEBVRE, 1978; MARX, 1983). Em razão das vantagens decorrentes da melhor localização ou da maior fertilidade, o preço individual de produção em determinado solo é menor que o preço social de produção, o qual é fornecido pelo "pior" solo, propiciando-lhe a extração de renda diferencial I (MARX, 1983).

Neste quesito, conforme afirma Oliveira (2007), os transportes são deveras importantes para o atributo localização da renda diferencial I, cujo grau de variação é elevado, enquanto a fertilidade natural possui menor variabilidade neste item. A proximidade com relação ao mercado consumidor também é crucial à formação desta renda. A redução dos custos concernentes aos transportes, em virtude de seus avanços, resulta em acréscimos na renda diferencial I, pois abrevia o tempo despendido no deslocamento. 
Ademais, o solo nepomucenense, de modo geral, possui elevada fertilidade natural, sendo propício à cafeicultura, conforme ilustram as narrativas elaboradas pela Prefeitura Municipal de Nepomuceno (1922), escritas há quase cem anos. De acordo com a obra, este foi um fator impulsionador da migração para o município. $\mathrm{O}$ fato acima explicitado também eleva a renda diferencial I no município. Adverte-se aqui, que a inserção de capitais é desconsiderada na análise desta forma de renda fundiária.

O caso de Nepomuceno, devido à distinta fertilidade natural de suas terras e à ocupação pelas lavouras cafeeiras há mais de um século, é basilar para a explicação de uma lei regente do comportamento da gênese da renda da terra diferencial I, decorrente das dessemelhanças na fertilidade natural dos solos. Nos dizeres de Oliveira (2007, p. 46), quando um país expande sua agricultura a partir dos terrenos de maior fertilidade em direção aos menos férteis, aqueles proprietários detentores do monopólio das "melhores" terras ampliarão suas rendas na mesma proporção em que são iniciados os cultivos nos "piores" solos, em virtude da necessidade ascendente da produção de alimentos.

Posto isto, os agricultores proprietários dos solos mais férteis pressionam os Estados para que estes incentivem a propagação da agricultura para terrenos de menor fertilidade, algo apenas viável com a expansão da aplicação de capitais no solo, gerando a renda diferencial II, de cunho técnico. De acordo com Lefebvre (1978; 1999) e Marx (1983), a renda diferencial II é uma renda técnica, a qual é auferida através de investimentos de capitais e técnicas nos solos, visando acréscimos na fertilidade e, por conseguinte, na produtividade. Destarte, é uma renda notoriamente capitalista. Sua fertilidade é artificial, visto que decorre da aplicação de insumos no solo, tais como fertilizantes químicos, agrotóxicos, sementes transgênicas, uso de maquinários agrícolas, entre outros (OLIVEIRA, 2007; HARVEY, 2013).

Harvey (2013) narra que a aplicação de capitais e técnicas nos solos incide em melhorias permanentes, as quais possibilitam a extração de renda diferencial II. Ademais, também demonstra que os investimentos na construção ou na melhoria das vias de circulação e dos meios de transporte também propiciam a obtenção desta forma de renda. Marx (1983) expõe que a renda diferencial I e a renda diferencial II são indissociáveis, visto que, de modo geral, os capitais são investidos nos solos naturalmente mais férteis ou de melhor localização, no intuito de maximizar os lucros. O autor também disserta que em razão das dessemelhantes localizações e fertilidades naturais dos solos, a quantidade de capitais aplicados neles também é díspar. 
Não obstante, os agricultores municipais, inclusive os familiares, utilizam táticas para elevação da fertilidade natural do solo, como por exemplo, a adição de adubos e fertilizantes químicos, configurando a formação de renda diferencial II. Neste caso, percebe-se que a renda diferencial I e a diferencial II podem se mesclar. Por isto, conforme advoga Harvey (2013), é cogente que elas não sejam avaliadas de forma dicotômica.

Neste âmbito, vale sublinhar a impossibilidade de se apresentar valores quanto às rendas diferencial I e II, visto que localização e fertilidade natural não são grandezas quantitativas, mensuráveis. Por esse motivo, precisar valores exatos para elas é uma tarefa inexequível. No entanto, deve-se advertir que as distintas formas de renda se manifestam empiricamente através dos preços e arrendamentos, os quais possibilitam a observação de suas oscilações e diferenças.

Quanto à renda diferencial II, em sua relação com a questão alimentícia reside uma contradição, pois ao passo que a aplicação de capitais e técnicas no solo acarreta no acréscimo da produtividade agrícola, pode também incidir na deterioração da qualidade dos alimentos cultivados, na alteração dos tipos de produtos cultivados, com expressivos deslocamentos produtivos.

O uso de maquinários e fertilizantes, por exemplo, aumenta o total produzido por área, contribuindo para a minoração dos índices de insegurança alimentar e de fome. Paradoxalmente, o uso dos agrotóxicos contribui para elevar a insegurança alimentar, pois é comprovado que os pesticidas provocam diversas moléstias ao organismo humano, como doenças mentais degenerativas, neoplasias, entre outras (PORTO-GONÇALVES, 2006).

Conforme exposto em trechos anteriores, a maioria das propriedades familiares rurais investigadas utiliza agrotóxicos em seus cultivos. $\mathrm{O}$ uso destes produtos químicos aclara um importante elemento do contexto agrícola nepomucenense, demonstrando que a renda da terra diferencial II é auferida até mesmo nas menores propriedades. Considerando-se que a estrutura fundiária municipal é caracterizada pelo elevado número de minifúndios e pequenas propriedades rurais, este fato corrobora a importância da renda diferencial II para o município nos tempos recentes.

Concordando com os dizeres de Oliveira (2007), apregoa-se que os melhoramentos genéticos nas sementes também podem ocasionar a formação de renda diferencial II, pois reverberam no acréscimo da produtividade agrícola. Sendo assim, os grãos transgênicos utilizados no município de Nepomuceno, preponderantes principalmente nas culturas de 
milho, contribuem para a extração de renda diferencial II nos solos locais.

Em consonância com Marx (1983), advoga-se que na renda diferencial II há a aplicação constante de capitais no solo, elevando sua produtividade e diminuindo o preço relativo da produção. Contudo, este aumento da eficiência produtiva pode ser preocupante, visto que se a demanda de um produto já for suprida pelo que era produzido anteriormente, este acréscimo na produção formará um excedente, podendo suscitar uma redução do valor venal dos gêneros agrícolas produzidos.

Assim, em conformidade com autores como Harvey (2013) e Oliveira (2007), percebe-se que no contexto recente, com o crescimento e a difusão das técnicas de produção, a renda diferencial I, aquela referente aos atributos naturais do solo, a fertilidade e a localização, perde importância. Enquanto isto, a renda diferencial II se valoriza, devido aos avanços nos setores de transportes, na química industrial, entre outros.

Atualmente, a fertilidade é um produto social, visto que quase todos os solos globo afora, até mesmo aqueles cultivados por pequenos fazendeiros, recebem adubos ou fertilizantes artificiais (HARVEY, 2013). A fala do geógrafo inglês é elucidativa quanto à questão abordada, pois ratifica a menor relevância da fertilidade natural dos solos no contexto vigente, acarretando no crescimento da renda diferencial II, em detrimento da renda diferencial I. Acerca deste processo, o próprio Harvey (2013, p. 459) explana:

\footnotetext{
Como em geral, os investimentos de capital na agricultura são efetivados nos solos de melhor qualidade, há uma maior concentração da produção nestas terras, conduzindo a uma diminuição nos preços de mercado e à redução da renda diferencial I, visto que a produção nos solos de pior qualidade pode ser completamente interrompida. Deste modo, a regulação dos preços de mercado seria fornecida para os melhores solos, pois não haveria produção naqueles qualitativamente inferiores.
}

O excerto acima mostra que apesar dos comentários construídos, a renda diferencial I não deve ser totalmente desprezada para a compreensão da atual lógica fundiária. Muitos capitalistas utilizam como tática para minimização dos custos produtivos a aplicação de capitais em solos onde a fertilidade já é originalmente elevada.

Estas ações são usuais no contexto nepomucenense, visto que as terras do município têm sua fertilidade reconhecida há tempos, conforme divulgou o Livro do Centenário, escrito pela Prefeitura Municipal de Nepomuceno (1922). Nestes casos, as rendas da terra diferencial I e II são conjugadas na mesma porção de terra, visto que a renda diferencial II é ampliada onde a renda diferencial I já era alta. 
Para Harvey (2013), a renda diferencial II só pode ser auferida tendo como base a renda diferencial I. Deste modo, mesmo que se aplique intensivamente capital no solo, sua localização e sua fertilidade natural prosseguirão sendo relevantes e contribuirão para a ocorrência da renda da terra. Ademais, ressalta-se que, segundo explana Marx (1983), a renda diferencial deriva do caráter capitalista das relações de uso e apropriação do solo, da concorrência, e não da propriedade privada, como ocorre na renda absoluta.

Neste enredo, alguns adendos são válidos quanto aos liames entre o setor industrial e o agrícola, sobretudo no tocante à renda fundiária. Conforme elucida Costa Neto (1998), ao fornecer alimentos a baixos preços à população, o pequeno agricultor propicia a acumulação em outros ramos, como o industrial. As necessidades de reprodução do capital no setor industrial são responsáveis por promover uma fixação dos preços agrícolas, geralmente, em níveis reduzidos. O rebaixamento dos preços dos alimentos eleva a mais-valia extraída no trabalho agrícola, assim como amplia o trabalho gratuito exercido e fornecido ${ }^{7}$ pelo agricultor familiar mercantil à sociedade.

Assim, uma parcela expressiva da renda fundiária migra para o capital industrial, em detrimento do agricultor familiar. Através da oferta de crédito, amplamente disseminada com a transição do fordismo para a acumulação flexível, o setor financeiro se apossa da parcela da renda fundiária "não-realizada". Deste modo, tal processo acarreta na expansão dos lucros empresariais, concordando com a premissa marxista, a qual apregoa a busca incessante dos capitalistas pela maximização dos lucros. Portanto, a contração dos preços agrícolas interessa tanto às indústrias urbanas, quanto às agroindústrias. Desta maneira, os atores capitalistas apoderam-se da renda da terra agrícola através da circulação das mercadorias (COSTA NETO, 1998).

É válido um comentário referente à renda da terra "não-realizada". Nos dizeres de Costa Neto (1998), a renda "não-realizada" é aquela ainda não transformada em valor. Existem duas formas de renda da terra "não-realizada". São denominadas "teses das rendas" e agrupam-se em renda presente e renda futura ou virtual. Conforme ilustra Vergopoulos (1977), a renda presente "não-realizada" ocorre quando o capitalismo financeiro-industrial consegue controlar a renda da terra, direcionando-a para outros setores. Para tal, é necessário que o trabalho gratuito do pequeno agricultor seja usado por outros ramos econômicos.

\footnotetext{
${ }^{7} \mathrm{O}$ trabalho gratuitamente fornecido pelo pequeno produtor agrícola procede da diferença entre o tempo de trabalho despendido por ele e o tempo de trabalho convertido em preço.
} 
Parcelas desta renda "não-realizada" são voltadas para os setores industrial-urbano e agroindustrial.

$\mathrm{Na}$ renda futura ou virtual, o agricultor mantém o domínio de suas atividades, apesar dos empecilhos que o impedem de auferir renda fundiária. Assim, ele aguarda que a especulação fundiária promova a realização da renda da terra, compensando os prejuízos trazidos pelos diminutos preços dos gêneros agrícolas (VERGOPOULOS, 1977).

Já no contexto nepomucenense, muitos pequenos agricultores informaram que mesmo com a atual crise alimentar mundial, o preço venal dos alimentos produzidos manteve-se praticamente estagnado, com aumentos inexpressivos. Por conseguinte, a mais-valia extraída no campo em Nepomuceno ampliou-se, fato que pode provocar o êxito do mecanismo supracitado de acumulação capitalista, no qual os lucros auferidos são apossados pelas finanças e indústrias. Assim, ratificam-se as muitas articulações existentes entre a pequena produção agrícola familiar, preponderante em Nepomuceno, e o capitalismo, conforme já expunha Marx (1983), em pleno século XIX.

Parte da renda da terra local é convergida e apropriada pelo setor financeiro-industrial, por exemplo, através da alargada oferta de crédito aos pequenos produtores agrícolas municipais e por intermédio da compra dos gêneros alimentícios cultivados no campo municipal a preços irrisórios. Neste processo, os agricultores familiares municipais fornecem trabalho gratuitamente a outros ramos econômicos, em virtude dos obstáculos que os atravancam na extração da renda fundiária.

Deste modo, em Nepomuceno, assim como em diversas outras localidades na superfície terrestre, a riqueza gerada pelos pequenos produtores agrícolas é desviada para as classes sociais dominantes. Em consonância com os dizeres de Oliveira (1981), pode-se afirmar que a estratégia de pagamento de reduzidos preços aos gêneros agrícolas favorece tal mecanismo, além de diminuir o custo de vida do proletariado urbano, tornando menos onerosa a reprodução da mão de obra e, consequentemente, propiciando a contração de suas remunerações, como maneira de ampliar as taxas capitalistas de lucros.

A renda fundiária pode se apresentar sob as formas de renda em trabalho, em produtos e em dinheiro, as quais compõem os tipos de renda fundiária pré-capitalista ${ }^{8}$, existindo até os tempos hodiernos. Quanto à renda em trabalho, Marx (1983, p. 905-910) a considera como a forma mais simples e antiga da renda fundiária. Como o trabalho é antecedente à produção e

\footnotetext{
${ }^{8}$ Neste item, em conformidade com Marx (1983), é válido acentuar que a renda da terra pré-capitalista tem sua gênese na produção, enquanto a renda fundiária capitalista é oriunda da distribuição da mais-valia.
} 
ao dinheiro, a renda dele oriunda também é anterior em relação às demais.

Ela possui um caráter tipicamente feudal, e corresponde ao quantum de trabalho gratuito despendido e fornecido pelo arrendatário ao proprietário das terras. Neste caso, a renda da terra é imediatamente o trabalho excedente não-pago. Contudo, para sua existência, é imperioso que a fertilidade natural da terra seja, no mínimo, suficiente para propiciar a extração de trabalho excedente (MARX, 1983).

A renda em trabalho pode ser convertida em renda em produtos. Nesta transformação, não há alterações no fator econômico da renda fundiária, visto que o produto é uma corporificação do trabalho excedente de outros. Na renda em produtos, o arrendatário concede parte do total produzido ao senhor das terras (MARX, 1983).

Frisa-se que na renda em trabalho, assim como na renda em produtos, a renda fundiária é uma feição natural da mais-valia e do trabalho excedente. Após a renda fundiária em trabalho ser transformada em renda em produtos, ela se metamorfoseia, originando a renda em dinheiro. O próprio Marx (1984) considera o dinheiro como a forma comum do valor das mercadorias, além de ser a mais evoluída.

Neste âmbito, alguns adendos são válidos quanto à forma dinheiro da mercadoria. Assim como Marx (1984) expõe, o dinheiro surge quando a forma natural da mercadoria se funde socialmente com a sua forma equivalente. $\mathrm{Na}$ forma dinheiro, a forma equivalente geral se une à forma natural específica da mercadoria ouro. Ela esconde o caráter social dos trabalhos privados e as relações sociais entre os produtores privados. Sendo assim, o dinheiro é valor porque é mercadoria como qualquer outra e, assim, é fruto do trabalho humano. Ademais, configura-se como a expressão monetária comum das mercadorias.

De acordo com as palavras de Marx (1983), a renda em dinheiro é obtida quando é pago um preço em dinheiro ao arrendador das terras, pelo seu aluguel. Para tal, é necessário que parcela dos víveres produzidos pelo arrendatário seja convertida em mercadoria, por intermédio da venda. Neste domínio, a renda em dinheiro supõe um progresso do comércio, da circulação monetária, da urbanização, entre outros fatores. Nela, a renda fundiária não mais coincide com a mais-valia e o trabalho excedente. Doravante, o foco do arrendatário é a produção de mercadorias volvidas à venda, em detrimento da produção direcionada à subsistência. Isto a discerne das rendas em trabalho e em produtos, acentuando sua natureza capitalista.

A renda fundiária pré-capitalista em Nepomuceno ocorre por intermédio da renda em 
produtos e da renda em dinheiro, as quais presumem maior desenvolvimento do trabalho e da sociedade como um todo, visto que nelas não há mais coação ou controle direto do proprietário das terras em relação aos arrendatários. Nestes casos, é a lei, e não mais a violência ou imposição física, que assevera o pagamento do arrendamento. Contudo, os contratos são, em si, coercitivos (MARX, 1983). Assim sendo, na renda em dinheiro, a exploração ocorre pelo acordo monetário, garantido pela legislação vigente.

A renda em dinheiro se realça no município analisado, visto que um significativo percentual dos arrendamentos efetivados é baseado na cobrança de quotas monetárias. Este modo de renda possui um viés notoriamente capitalista, inserindo profundamente o capital oriundo das urbes na dinâmica agrícola.

Esta situação é apreendida na realidade nepomucenense, cuja agricultura (não somente ela) é subordinada a diversas relações e processos explicitamente capitalistas. Além disto, corroborando tal colocação, conforme já aventado, é evidente a inserção de capitais urbanoindustriais, como técnicas e insumos, no campo nepomucenense.

Contemporaneamente, há uma subordinação da renda da terra ao capital, pois o camponês está amalgamado ao setor financeiro-industrial em seu processo produtivo, com relações capitalistas envoltas à sua produção. Por exemplo, no contexto analisado, ao venderem parte expressiva de suas produções às cooperativas, as quais as repassam às grandes indústrias, os pequenos agricultores familiares estão com a renda da terra auferida submetida aos interesses capitalistas. Sublinha-se que no decurso da história, a expansão e o desenvolvimento do capitalismo no campo ocorreram através da submissão da renda fundiária ao capital (COSTA NETO, 1998).

Para além, a oferta de crédito aos agricultores camponeses os torna dependentes, assim como ocorre com a renda da terra (OLIVEIRA, 2007). Como são muitas as possibilidades e as modalidades de empréstimos oferecidas aos pequenos produtores nepomucenenses, eles ficam à mercê dos mecanismos capitalistas de extração de mais-valia, ampliação e reprodução do capital.

Nos dizeres de Oliveira (1981), o Estado media e propulsiona o processo de sujeição do camponês e da renda da terra ao capital, atuando como agente em prol dos interesses capitalistas, como explana Amin (1977), Erthal (2006), entre outros autores. No atual panorama nacional, a circulação e a comercialização de mercadorias agrícolas foram intensificadas, elevando a quantidade de renda fundiária drenada para outros setores, como o 
comercial, o industrial, entre outros.

Os atores estatais, por intermédio de créditos bancários e programas de financiamentos, acirram a dependência do pequeno produtor em relação ao capital financeiro industrial, através de seu endividamento (COSTA NETO, 1998). Neste item, o Programa Nacional de Fortalecimento da Agricultura Familiar (PRONAF), assim como outros programas, amplamente disseminados em Nepomuceno, mesmo concedendo empréstimos a diminutos índices de juros aos agricultores familiares, estreita seus vínculos com outros ramos econômicos.

A título de exemplo, a maioria dos fertilizantes e adubos químicos consumidos no território nacional é comprada através de empréstimos favorecidos pelo Estado brasileiro, cujas ações beneficiam o setor industrial, pois estimulam o consumo de seus produtos (OLIVEIRA, 1981). Neste ponto, a realidade nepomucenense não se distingue da nacional, visto que a parcela majoritária dos financiamentos efetivados pelos agricultores municipais possui como intuito a aquisição de mercadorias oriundas das indústrias, principalmente pesticidas, maquinários, fertilizantes químicos, entre outras. Portanto, os empreendimentos estatais em solo pátrio privilegiam os agentes capitalistas e auxiliam na absorção de parcela da renda da terra originada no trabalho agrícola pelo capital, através das relações sociais de produção vigentes em sua conjuntura agrícola (OLIVEIRA, 2007).

Conforme expõem Costa Neto (1998) e Oliveira (2007), a transferência da renda fundiária agrícola às corporações industriais monopolistas acontece por intermédio da circulação de produtos industriais em direção à agricultura e através da circulação das matérias-primas originadas na agricultura para atividades industriais. $\mathrm{O}$ enlace entre estes dois setores econômicos se intensifica paulatinamente nos tempos contemporâneos, demonstrando que não podem ser avaliados de forma dicotômica.

Em Nepomuceno, é frequente a compra de insumos industriais tanto pelos pequenos proprietários agrícolas, quanto pelos arrendatários, no propósito de elevar a produtividade de suas terras. Ademais, a maioria dos víveres cultivados na agricultura familiar municipal é comercializada com empresas urbano-industriais, as quais pagam irrisórios valores por estas mercadorias, deteriorando as condições de vida dos agricultores familiares locais.

Através destas artimanhas, a renda fundiária agrícola nepomucenense, assim como em diversos outros locais, é subordinada e dirigida ao capital industrial, o qual maximiza seus dividendos e ratifica sua hegemonia nas mais variadas escalas (COSTA NETO, 1998; 
OLIVEIRA, 2007). Assim, o modo de produção capitalista utiliza a estratégia de sujeição da renda da terra ao capital como principal mecanismo para sua expansão.

A subordinação da renda da terra ao capital suscita diversos prejuízos ao trabalhador agrícola, pois ao ser expropriado dos meios produtivos, a única opção remanescente é a venda de sua força de trabalho aos capitalistas, na qual há profunda extração de mais-valia, além da exploração deste operariado em árduas rotinas de labor (OLIVEIRA, 1981). Contudo, em alguns casos presenciados no município, há a sujeição da renda da terra ao capital sem que os agricultores familiares sejam expropriados de seus meios produtivos.

Esta situação é encontrada na conjuntura agrícola nepomucenense, na qual, em razão da escassez de opções de emprego, os trabalhadores se submetem a funções desgastantes e muito mal remuneradas, sobretudo na época da colheita do café, entre os meses de maio e setembro. No restante do ano, uma parcela destes indivíduos procura emprego na cidade, atuando principalmente em funções que demandam baixo nível de escolaridade formal.

Destarte, com o aprofundamento das relações capitalistas no campo brasileiro, ampliou-se o proletariado rural, em virtude do êxodo rural, da elevada concentração e da especulação fundiária, entre outras causas (VERGOPOULOS, 1977). Oliveira (1981) assinala que há algumas décadas, as classes hegemônicas, associadas às finanças e às indústrias, estão inserindo relações de caráter capitalista no campo brasileiro, em detrimento das condições de vida e de trabalho de seus habitantes, fato constatado em Nepomuceno, onde a míngua de empregos no campo é algo latente.

\section{CONSIDERAÇÕES FINAIS}

Quanto à renda da terra de cunho capitalista, notou-se uma intensa presença de renda da terra diferencial II, a qual representa a renda agrícola derivada da aplicação de técnicas e capitais no solo, com o intuito de maximizar sua fertilidade. A inserção das modificações na produção agrícola decorrentes da Revolução Verde e da Modernização Agrícola, como a mecanização do processo produtivo e o uso de insumos, como os pesticidas e os transgênicos, colaboraram para o aumento desta renda técnica no município, em virtude da elevação da produtividade agrícola.

Embora nos tempos recentes, a renda diferencial II se destaque em comparação à renda diferencial I, esta não pode ser desprezada. Destarte, os solos situados no território municipal extraem a renda diferencial I, devido à sua ótima localização e à sua alargada 
fertilidade natural. A renda absoluta também existe de maneira marcante em Nepomuceno, visto que os arrendamentos são rotineiros no campo local. Ademais, os produtores agrícolas municipais vendem seus produtos acima do preço de produção, também auferindo renda absoluta por tal procedimento, apesar da estagnação dos preços dos gêneros agrícolas.

Considerando-se que os agricultores, visando algum lucro, vendem os alimentos cultivados acima do preço de produção, estes auferem renda absoluta, pois conforme apregoam Marx (1983) e Oliveira (2007), até o solo com piores qualidades consegue auferila, visto que a renda absoluta é obtida através da venda das mercadorias a um preço maior que o de produção.

As formas pré-capitalistas de renda fundiária existentes em Nepomuceno são a renda em produtos e a renda em dinheiro, com predomínio da última. Em ambas, o arrendatário não é coagido fisicamente para produzir. No entanto, o contrato assinado, por intermédio da obrigatoriedade jurídica, o impele ao cumprimento dos acordos instaurados e ao ímpeto produtivo.

Portanto, na maioria dos arrendamentos realizados, o pagamento é feito em dinheiro, enquanto no restante, o pagamento é efetuado com a cobrança de um percentual da produção. Como a renda em dinheiro é prevalente no município, isto implica na inserção de capitais urbano-industriais na agricultura e no campo, situação constatada na pesquisa através das entrevistas semiestruturadas realizadas, pois diversos artefatos citadinos e industriais, como maquinários, pesticidas e grãos transgênicos, são utilizados na produção.

\section{REFERÊNCIAS}

AMIN, Samir. "O capitalismo e a renda fundiária (A dominação do capitalismo sobre a agricultura”. In: A Questão Agrária e O Capitalismo. AMIN, Samir. \& VERGOPOULOS, Kostas. Tradução: Beatriz Resende. Rio de Janeiro: Editora Paz e Terra, 1977. p. 09-42.

BRASIL. Projeto RadamBrasil: Pedologia: levantamento exploratório de solos. Ministério de Minas e Energia. Secretaria Geral, Rio de Janeiro. Folhas SF-23/24, Rio de Janeiro/Vitória. 1983. p. 385-552.

Lei $\mathrm{n}^{0}$. 8.629, de 25 de fevereiro de 1993. Disponível em:

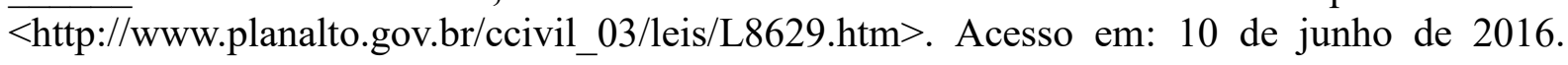
1993.

COSTA NETO, Canrobert. Agricultura familiar e renda da terra. Estudos Sociedade e Agricultura, n. 10, 1998, p. 118-134. 
ERTHAL, Rui. Os Complexos Agroindustriais no Brasil - Seu Papel na Economia e na Organização do Espaço. Revista Geo-Paisagem (Online). Ano 5, n. 9, 2006.

GIL, Antonio Carlos. Como Elaborar Projetos de Pesquisa. 4ª Edição. São Paulo: Editora Atlas, 2002.

HARVEY, David. Os Limites do Capital. Tradução: Magda Lopes. São Paulo: Editora Boitempo, 2013.

IBGE - INSTITUTO BRASILEIRO DE GEOGRAFIA E ESTATİSTICA. Censo Demográfico - 1991. 1991.

Censo Demográfico - 2000. 2000.

Censo Demográfico - 2010. 2010.

Produção Agrícola Municipal - Culturas temporárias e permanentes. Vol. 40. Rio de Janeiro. 2013.

LACOSTE, Yves. A Pesquisa e o Trabalho de Campo: Um Problema Político para os Pesquisadores, Estudantes e Cidadãos. Boletim Paulista de Geografia. n. 84. São Paulo. 2006, p. 77-92.

LEFEBVRE, Henri. De lo Rural a lo Urbano. $4^{\text {a }}$ Edição. Barcelona: Ediciones Península, 1978.

A Cidade do Capital. Rio de Janeiro: Editora DP\&A, 1999.

MARX, Karl. O Capital (Crítica da Economia Política) - Livro 3 - O Processo Global de Produção Capitalista. Volume VI. Tradução: Moacyr Félix. $3^{\mathrm{a}}$ Edição. Rio de Janeiro: Editora Civilização Brasileira. 1983, p. 705-1079.

O Capital. (Crítica da Economia Política) - Volume I. Tomo II. Tradução: Régis

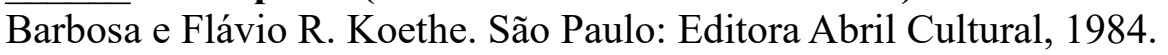

OLIVEIRA, Ariovaldo Umbelino de. Agricultura e Indústria no Brasil. Boletim Paulista de Geografia. n. 58. São Paulo: Associação dos Geógrafos Brasileiros (AGB). 1981, p. 05-64.

Modo Capitalista de Produção, Agricultura e Reforma Agrária. $1^{\mathrm{a}}$ Edição. São Paulo: FFLCH/ Labur Edições, 2007.

OLIVEIRA, Maria Marly de. Como fazer pesquisa qualitativa. $4^{\text {a }}$ Edição. Petrópolis: Editora Vozes, 2012.

PORTO-GONÇALVES, Carlos Walter. A Globalização da Natureza e a Natureza da Globalização. Rio de Janeiro: Editora Civilização Brasileira, 2006.

PREFEITURA MUNICIPAL DE NEPOMUCENO. Livro do Centenário. 1922.

SANTOS, Milton. A Natureza do Espaço. Técnica e Tempo. Razão e Emoção. $4^{\mathrm{a}}$ Edição. $2^{\mathrm{a}}$ Reimpressão. São Paulo: EdUSP (Editora da USP), 2006. 
O Espaço Dividido: Os Dois Circuitos da Economia Urbana dos Países Subdesenvolvidos. São Paulo: EdUSP (Editora da USP), 2008.

TRIVIÑOS, Augusto Nibaldo Silva. Introdução à Pesquisa em Ciências Sociais - A Pesquisa Qualitativa em Educação. 4a Edição. São Paulo: Editora Atlas, 1995.

VERGOPOULOS, Kostas. "Capitalismo disforme (O caso da agricultura no capitalismo)". In: A Questão Agrária e O Capitalismo. AMIN, Samir. \&

VERGOPOULOS, Kostas. Tradução: Beatriz Resende. Rio de Janeiro: Editora Paz e Terra, 1977. p. 43-179.

Recebido em Janeiro de 2016

Aprovado em Maio de 2016

Publicado em Junho de 2016

Sociedade e Território - Natal. Vol. 28, N. 1, p. 48-69. Jan./Jun. de 2016 